\title{
Natural analogues for atmospheric carbon dioxide removal by enhanced basalt weathering
}

\section{SIGURDUR R GISLASON AND TOBIAS LINKE}

Institute of Earth Sciences, University of Iceland

Presenting Author: sigrg@hi.is

Enhanced Rock Weathering (ERW) has been proposed as an important method for carbon dioxide removal from the atmosphere, and as an essential pathway for making global agriculture net carbon -negative in the second half of this century. ERW involves amending soils with crushed, fastreacting $\mathrm{Ca}-\mathrm{Mg}$-silicate minerals and rocks, such as basalt. Field experiments have demonstrated enhanced crop vigour and health, higher soil organic and sometimes inorganic carbon storage, and less degassing of $\mathrm{N}_{2} \mathrm{O}$, which is a strong greenhouse gas [1-3].

The annual mass load $\left(\sim 20 \mathrm{tha}^{-1} \mathrm{y}^{-1}\right)$ of the crushed $(\sim 100 \mu \mathrm{m})$ $\mathrm{Ca}-\mathrm{Mg}$-silicates in these experiments is comparable to the maximum global fertilizer use on arable land $[2,3]$. The highest aeolian dust load on Earth, as in central Iceland (2- $8 \mathrm{t} \mathrm{ha}^{-1}$ $\left.\mathrm{y}^{-1}[4]\right)$, is lower than in the ERW experiments, but yields the same reactive surface area load, due to the fine-grained nature of the dust. The majority of this dust is basaltic glass [4], which makes the "dusty" Icelandic vegetated and cultivated land area an ideal natural analogue to define the short- and long-term effects of ERW-applications. The overall alkalinity and secondary mineral production of enhanced weathering, which stores carbon dioxide in the form of bicarbonate and possibly carbonate minerals can be quantified. Furthermore, heavy metals released from the basalt and metal mobility within the soil and in its runoff can be measured and compared with ERW-field experiments where crushed basalt has been applied.

[1] Beerling et al. (2020), Nature 583, 242-248.

[2] Haque, Chiang \& Santos (2019), Energies 12, 1-17.

[3] Gillman, Burkett \& Coventry (2002), Applied Geochemistry 17, 987-1001.

[4] Arnalds, Dagsson-Waldhauserova \& Olafsson (2016), Aeolian Research 20, 176-195. 